\title{
Correction to: Measurement of Activation Energy and Accelerated Degradation Time by Thermal Analysis Methods for Polymeric Insulating Materials
}

\author{
Heon-Gyeong Lee ${ }^{1} \cdot$ Jae-Seung Jung ${ }^{2} \cdot$ Jin-Gyu Kim $^{3}$
}

Published online: 16 April 2021

(c) The Korean Institute of Electrical Engineers 2021

\section{Correction to: \\ Journal of Electrical Engineering \& Technology (2021) 16:515-524. \\ https://doi.org/10.1007/s42835-020-00606-3}

Due to an unfortunate mistake, the Eq. 7 has been shown erroneously. It should read:

$\ln \left(\frac{d \alpha}{d t}\right)-\ln (1-\alpha)=\ln A-\left(\frac{E}{R T_{m}}\right)$

Further, the acknowledgment has been omitted. It should read:
Acknowledgements This research was supported by Korea Electric Power Corporation (Grant Number R17XA05-3).

Publisher's Note Springer Nature remains neutral with regard to jurisdictional claims in published maps and institutional affiliations.

The original article can be found online at https://doi.org/10.1007/ s42835-020-00606-3.

Jin-Gyu Kim

kjg@knu.ac.kr

Heon-Gyeong Lee

hglee0211@naver.com

Jae-Seung Jung

PR18063@koje.ac.kr

1 Department of Electrical Engineering, Kyungpook National University, Daegu, Korea

2 Department of Electrical Engineering, Koje College, Geoje, Korea

3 Department of Electrical Engineering, School of Electronic and Electrical Engineering, Kyungpook National University, Daegu, Korea 